\title{
AUTONOMIC DISEASES: MANAGEMENT
}

T he management of autonomic disease encompasses a number of aspects. Of immediate and practical importance is alleviation of symptoms. The ideal is to rectify the autonomic deficit and cure the underlying disorder. Autonomic disease often involves various systems, and principles in relation to management of the major clinical features are provided. Specific aspects will vary in different diseases and always should be directed to the needs of the individual.

\section{CARDIOVASCULAR SYSTEM}

\section{Orthostatic hypotension}

Orthostatic (postural) hypotension may cause few symptoms in some but considerable morbidity in others. It may contribute to disability and even death, because of the potential risk of substantial injury. Treatment may be needed even in those who are asymptomatic, as in situations such as fluid depletion or treatment with drugs that have vasodilator effects, there may be pronounced falls in blood pressure with serious sequelae. Understanding the pathophysiological basis of orthostatic hypotension, and the associated disease process that influences it, often is necessary in the individual.

Blood pressure maintenance is dependent on beat-by-beat control exerted by the sympathetic nervous system, on cardiac output, on tone in resistance and capacitance vessels (which also is influenced by systemic and local pressor and depressor hormones), and on intravascular fluid volume. No single drug or treatment can effectively mimic the actions of the sympathetic nervous system in different situations and a multipronged approach, combining non-pharmacological and pharmacological measures, usually is needed (table 1). The doctor and patient should be aware of the limitations of treatment. Furthermore, associated deficits (such as cerebellar features in multiple system atrophy) may limit mobility in some, despite effective treatment of orthostatic hypotension.

Increasing patient awareness of factors that lower blood pressure is important. Rapid postural change, especially in the morning when getting out of bed, must be avoided because the supine blood pressure often is lowest at this time. Prolonged bed rest and recumbency through factors that include decompensation may contribute to orthostatic intolerance, even in healthy individuals, and can considerably worsen orthostatic hypotension in autonomic failure. Head-up tilt at night is beneficial and may reduce salt and water loss by stimulating the renin-angiotensin-aldosterone system. Straining during micturition and defaecation lowers blood pressure further by inducing a Valsalva manoeuvre. In toilets in small enclosed areas this is dangerous because of the inability to fall to the floor and thereby recover blood pressure and consciousness. In hot weather, because of impairment of thermoregulatory mechanisms, the rise in body temperature will increase cutaneous vasodilatation and worsen orthostatic hypotension. Ingestion of alcohol or large meals, especially those with a high carbohydrate content, causes splanchnic vasodilatation and postprandial hypotension, which aggravate orthostatic hypotension. Various physical manoeuvres such as leg crossing, squatting, sitting in the knee-chest position, and abdominal compression, reduce orthostatic hypotension (fig 1). Drugs needed for associated symptoms (such as dopaminergic agents for parkinsonism) or to improve quality of life (sildenafil for erectile failure), may lower blood pressure further.

Lower limb elastic stockings, abdominal binders, and positive gravity suits reduce venous pooling during standing. Each has its limitations and may increase susceptibility to orthostatic hypotension when not in use. Water ingestion $(250-500 \mathrm{ml})$ raises blood pressure substantially in primary autonomic failure by mechanisms that remain unclear. The ensuing diuresis may be

Correspondence to: Professor C J Mathias,

Neurovascular Medicine Unit, Imperial College London at St Mary's Hospital, 2nd Floor, Queen Elizabeth The Queen Mother Wing, Praed Street, London W2 1NY, UK;

c.mathias@imperial.ac.uk bances.

Drugs often are needed in association with non-pharmacological measures in moderate to severe orthostatic hypotension. They may act in a variety of ways to raise blood pressure; by constricting blood vessels, increasing cardiac output, preventing vasodilatation, and retaining salt and water.

A valuable starter drug is fludrocortisone in a dose of 50-100 $\mu \mathrm{g}$ at night. Although there is no evidence of a mineralocorticoid deficiency in primary autonomic failure, it acts by retaining salt 
Table 1 Some of the approaches used in the management of orthostatic hypotension

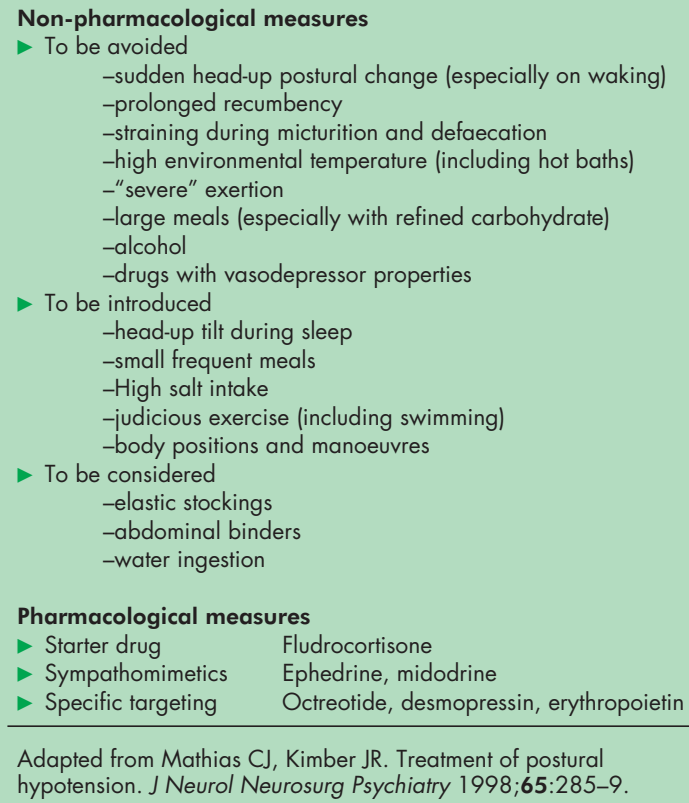

and water and increasing the sensitivity of blood vessels to pressor substances. Body weight may increase. In some ankle oedema, and with higher doses hyperkalaemia, may result.

The second line of drugs include those that mimic the actions of noradrenaline (norepinephrine). Sympathomimetics include ephedrine, used in a dose of $15 \mathrm{mg}$ three times daily that can be increased to 30 or $45 \mathrm{mg}$ three times daily. It acts both directly and indirectly. It raises blood pressure in central and incomplete autonomic lesions, including MSA. Tachycardia, tremor, and insomnia may limit use of higher doses. In peripheral lesions, such as pure autonomic failure (PAF) and diabetic autonomic neuropathy, where ephedrine may not be effective, midodrine is used. It is converted to the active metabolite, desglymidodrine, that acts on $\alpha$ adrenoceptors. An initial dose of $2.5 \mathrm{mg}$ three times daily can be increased gradually to $10 \mathrm{mg}$ three times daily. Its side effects include a tingling scalp, goose bumps, and in the male urinary retention. Knowledge of the precise biochemical deficit enables selective use of drugs that bypass the autonomic deficit, as in dopamine $\beta$ hydroxylase (DBH) deficiency, where the amino acid, 1-threo-3, 4-dihydroxyphenylserine is converted by dopa-decarboxylase into noradrenaline (fig 2). Sympathomimetic drugs act mainly on resistance vessels and consideration should be given to the potential risk of deleterious arterial constriction, especially in the elderly and those with peripheral vascular disease. The ergot alkaloid, dihydroergotamine, acts predominantly on venous capacitance vessels, but its effects are limited by its poor absorption necessitating high oral doses (5-10 mg three times daily).

Specific targeting of pathophysiological mechanisms should be introduced when the combination of fludrocortisone and sympathomimetics is not effective. Nocturnal polyuria often worsens morning orthostatic hypotension. The vasopressin-2 receptor agonist, desmopressin, is a potent antidiuretic with minimal direct pressor activity. It is used in a dose of 5-40 $\mu \mathrm{g}$ intranasally or $100-400 \mathrm{mg}$ orally at night to reduce diuresis. It ideally needs to be used with fludrocortisone to prevent nocturnal natriuresis. In MSA, with nocturia also caused by bladder disturbances, it may be of considerable benefit in reducing disturbed sleep. Smaller doses are needed in PAF who appear more sensitive than MSA. Plasma sodium should be measured at intervals to exclude hyponatraemia. Water intoxication can be reversed by stopping the drug, and withholding water.

In postprandial hypotension large meals should be avoided and small meals with low carbohydrate content eaten at frequent intervals. Drinking coffee after meals may help. Caffeine blocks vasodilatatory adenosine receptors, and a dose of $250 \mathrm{mg}$ (present in two cups of coffee) can be used; tolerance may develop. The somatostatin analogue, octreotide, prevents postprandial hypotension by inhibiting release of a variety of
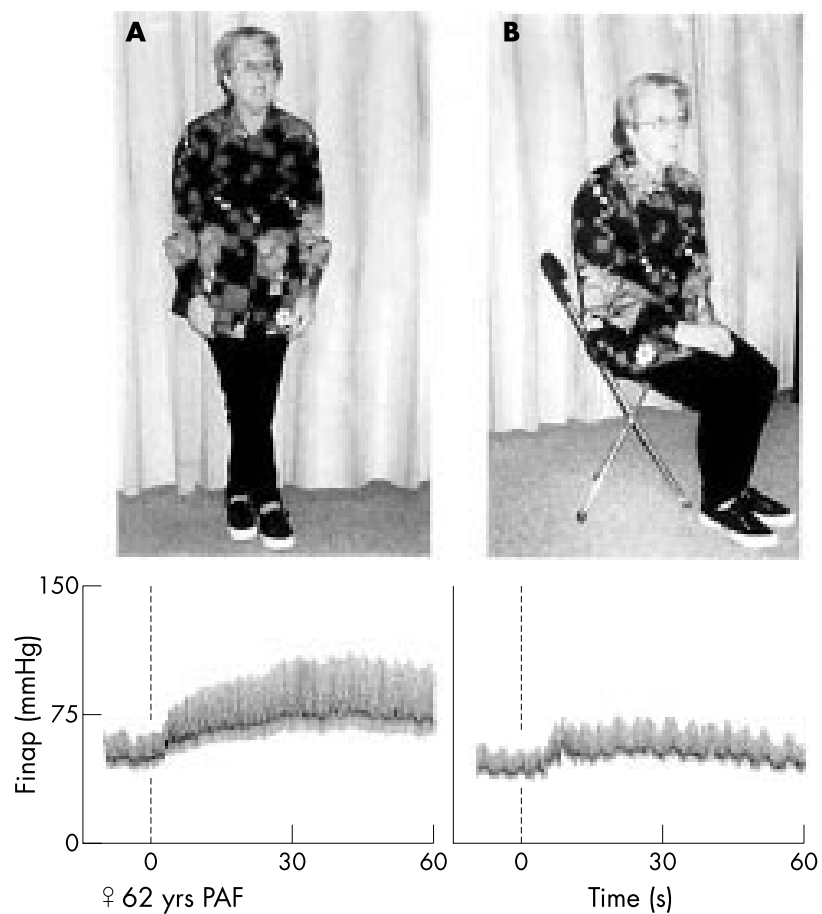
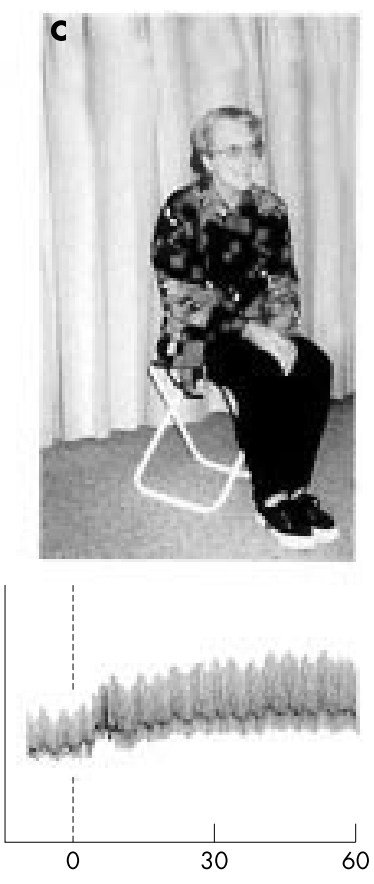

Figure 1 The effect of standing in a crossed-leg position with leg muscle contraction $(A)$, sitting in a derby chair (B), and fishing chair (C) on finger arterial blood pressure in a patient with orthostatic hypotension. Postural symptoms were present while standing and disappeared while crossing legs. Sitting on a derby chair did not completely relieve the patient's symptoms. Note the greater increment in blood pressure while standing with crossed legs and leg muscle contractions, or sitting in the fishing chair, compared with sitting on a derby chair. Reproduced from Smit AAJ, Hardjowijono MA, Wieling $W$. Are portable folding chairs useful to combat orthostatic hypotension? Ann Neurol 1997;42:975-8 


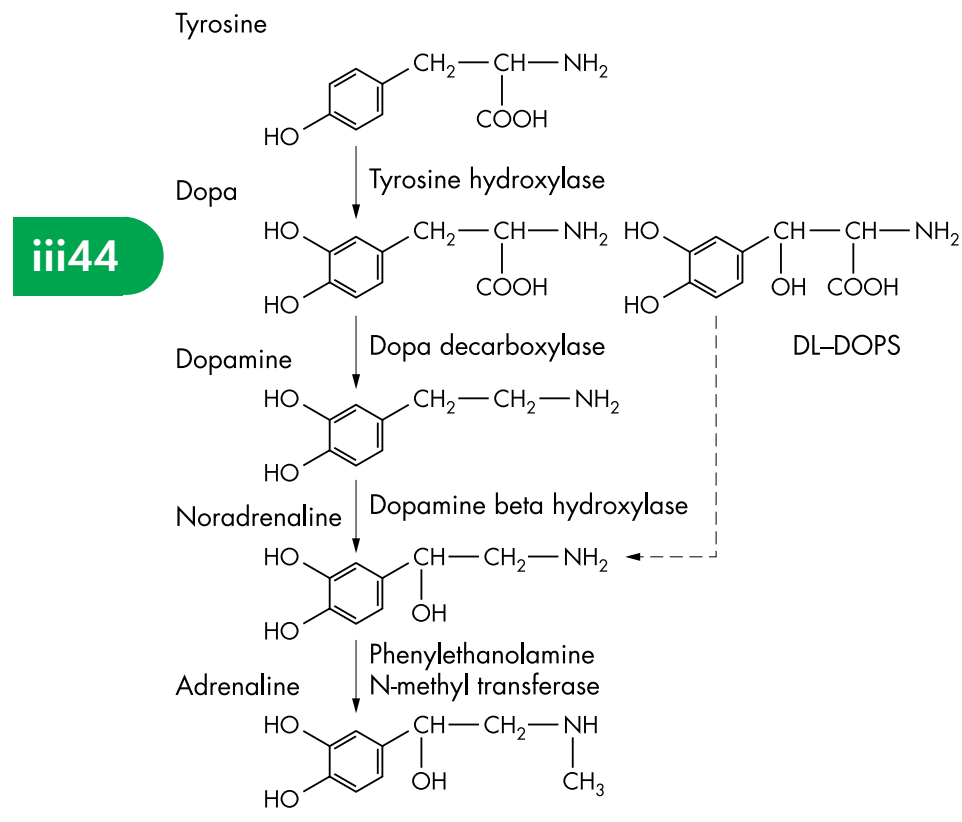

Figure 2 Biosynthetic pathway for noradrenaline sythesis and the structure of 1-threo 3,4-dihydroxyphenylserine alongside. The enzyme dopa-decarboxylase, which is present both intra- and extraneuronally, converts it to noradrenaline, thus bypassing the hydroxylation step, which depends on dopamine $\beta$ hydroxylase. Reproduced from Mathias CJ, et al. Clinical autonomic and therapeutic observations in two siblings with postural hypotension and sympathetic failure due to an inability to synthesize noradrenaline from dopamine because of a deficiency of dopamine beta hydroxylase. QJM, New Series 75 1990; 278:617-33.

vasodilatatory gastrointestinal peptides; it also may reduce postural and exercise induced hypotension. It is administered subcutaneously, in a dose of 25 or $50 \mu$ g, ideally 30 minutes before food ingestion. Its side effects include abdominal colic and loose stools that respond to spasmolytics (buscospan) and opiates (codeine phosphate and loperamide). Octreotide does not appear to enhance supine nocturnal hypertension.

Anaemia worsens the symptoms of orthostatic hypotension. It may occur in primary autonomic failure and when renal impairment complicates diabetes mellitus and systemic amyloidosis. Erythropoietin raises red cell mass and haemoglobin concentrations and reduces orthostatic hypotension and its symptoms in such situations.

Difficulties in the management of orthostatic hypotension have resulted in a vast array of drugs that in individual cases, or certain disorders, have been reported to provide benefit (table 2). When the drugs listed in table 1 fail, these could be considered. As with all drugs they should be used cautiously. Some have serious side effects such as cardiac failure with pindolol, and gastric ulceration and haemorrhage with indomethacin. The use of a noradrenaline pump in extreme cases has been beneficial.

Drugs to prevent orthostatic hypotension should be used to reduce the side effects of treatment that is essential for associated disease. When levodopa (L-dopa) is used to treat parkinsonism, higher doses of dopa-decarboxylase inhibitors should be used. The dopamine antagonists metoclopramide and domperidone also reduce the peripheral effects of dopamine.

\section{Supine hypertension}

Supine hypertension is frequently observed in primary autonomic failure and may be worsened by drug treatment. It
Table 2 Outline of the major actions by which a variety of drugs reduce orthostatic hypotension

- Reducing salt loss/plasma volume expansion

-mineralocorticoids (fludrocortisone)

- Reducing nocturnal polyuria

$-\mathrm{V}_{2}$ receptor agonists (desmopressin)

- Vasoconstriction: sympathetic

-on resistance vessels (ephedrine, midodrine, phenylephrine, noradrenaline, clonidine, tyramine with monoamine oxidase inhibitors, yohimbine, L-dihydroxyphenylserine) -on capacitance vessels (dihydroergotamine)

- Vasoconstrictor: non-sympathomimetic $-V_{1}$ receptor agents (terlipressin)

- Preventing vasodilatation -prostaglandin synthetase inhibitors (indomethacin, flurbiprofen) -dopamine receptor blockade (metoclopramide, domperidone) $-\beta_{2}$ adrenoceptor blockade (propranolol)

- Preventing postprandial hypotension -adenosine receptor blockade (caffeine) -peptide release inhibitors (somatostatin analogue: octreotide)

- Increasing cardiac output $-\beta$ blockers with intrinsic sympathomimetic activity (pindolol, xamoterol) -dopamine agonists (ibopamine)

Increasing red cell mass -erythropoietin

Adapted from Mathias CJ, Kimber JR. Postural hypotension - causes, clinical features, investigation and management. Annu Rev Med 1999;50:317-36

is unclear if certain drugs, such as higher doses of fludrocortisone, are more likely to cause it. Supine hypertension may increase symptoms of cerebral ischaemia during postural change through an unfavourable resetting of cerebral autoregulatory mechanisms. Head-up tilt especially at night is probably the most practical method for preventing nocturnal supine hypertension. Omission of the evening dose of vasopressor agents, a pre-bedtime snack or alcohol to induce postprandial hypotension, and sometimes even use of short acting antihypertensive drugs, should be considered.

The long term effects of supine hypertension include cardiac hypertrophy and damage to subcortical cerebral vessels. This may occur in PAF who have a good prognosis and in whom antihypertensive drugs may be used over many years. The benefits of effectively treating orthostatic hypotension, thus reducing the likelihood of trauma and improving their quality of life, should be weighed against the long term risks.

\section{Neurally mediated syncope}

This depends upon the cause, the provoking factors, the disability caused, and whether the episodes are of the cardioinhibitory, vasodepressor or mixed type. Vasovagal syncope usually carries an excellent prognosis. Once the diagnosis is confirmed an important component of management is positive reassurance. Advice on non-pharmacological measures should be provided. These include salt repletion, an adequate fluid intake, avoidance of excessive use of stimulating substances such as caffeine, and, when needed, methods to enhance sympathetic activity and prevent pooling. Sympathetic activation techniques to raise blood pressure include those used during autonomic testing, such as the use of isometric hand exercise. Sitting with the head between the knees often is an effective means of preventing syncope. 
There are a variety of measures to prevent venous pooling that include activation of the calf muscle pump during leg crossing and squatting while tying shoe laces. If necessary subjects should lie flat with the legs upright or with the head between the knees. Each subject should decide on which method to use effectively in different situations. This is of value especially in those who have a suitable window of warning before they lose consciousness. In vasodepressor syncope, if drugs are needed, low dose fludrocortisone and sympathomimetics can be used. Ephedrine is contraindicated if tachycardia is a problem; midodrine is the alternative. In those with a predominant cardio-inhibitory component a demand pacemaker needs consideration, especially when there is minimal warning before fainting. Cognitive behavioural psychotherapy is helpful if there is co-existing phobia, panic attack or anxiety disorder. The 5-hydroxytryptamine and noradrenaline uptake inhibitors also have a role.

In carotid sinus hypersensitivity, a cardiac demand pacemaker often is needed. When vasodepression persists following pacemaker insertion, vasopressor agents including midodrine should be considered. Caution should be exercised as these patients often are elderly and may have vascular disease or prostatic hypertrophy that increase the tendency to side effects. In unilateral hypersensitivity, carotid sinus denervation needs consideration.

In situational syncope, management should be directed towards the underlying cause and pathophysiological basis. In micturition syncope, that mainly occurs in the male, advice is needed to avoid factors (such as alcohol) which contribute; the bladder should be emptied while sitting rather than standing.

\section{Hypertension}

Hypertension caused by increased sympathetic nervous activity in the Guillain-Barré syndrome and subarachnoid haemorrhage may respond to propranolol and other sympatholytic agents. In high spinal cord injuries, determining and rectifying the provoking cause of autonomic dysreflexia is crucial, as the key is prevention. A range of drugs, based on knowledge of the pathophysiological mechanisms, can be used to prevent or reduce hypertension in such patients (table 3).

Table 3 Some of the drugs used in reducing hypertension in management of autonomic dysreflexia, classified according to their major site of action on the reflex arc and target organs

\begin{tabular}{|c|c|c|}
\hline - Afferent & & Topical lignocaine \\
\hline - Spinal cord & & $\begin{array}{l}\text { Clonidine* } \\
\text { Reserpine* } \\
\text { Spinal anaesthetics }\end{array}$ \\
\hline - Efferent & $\begin{array}{l}\text { Sympathetic ganglia } \\
\text { Sympathetic nerve terminals } \\
\alpha \text { Adrenoceptors }\end{array}$ & $\begin{array}{l}\text { Hexamethonium } \\
\text { Guanethidine } \\
\text { Phenoxybenzamine }\end{array}$ \\
\hline $\begin{array}{l}\text { Target } \\
\text { organs }\end{array}$ & Blood vessels & $\begin{array}{l}\text { Glyceryl trinitrate } \\
\text { Nifedipine }\end{array}$ \\
\hline $\begin{array}{l}\text { *Clonidine an } \\
\text { peripheral. } \\
\text { Adapted from } \\
\text { spinal cord les } \\
\text { failure: a textb } \\
\text { system, } 4 \text { th ed }\end{array}$ & $\begin{array}{l}\text { serpine have multiple effect } \\
\text { hias CJ, Frankel HL. Autono } \\
\text { In: Mathias CJ, Bannister } \\
\text { of clinical disorders of the } \\
\text { xford: Oxford University Pre }\end{array}$ & $\begin{array}{l}\text { some of which are } \\
\text { hic disturbances in } \\
\text { eds. Autonomic } \\
\text { utonomic nervous } \\
\text {, 2002:494-513. }\end{array}$ \\
\hline
\end{tabular}

\section{SUDOMOTOR DISORDERS}

\section{Anhidrosis}

The ensuing problems include dry skin, hyperthermia, and vasomotor collapse in hot weather. Dry skin is helped by suitable emollients. Prevention of hyperthermia is important by avoiding exposure to heat and ensuring a suitable microenvironment ideally by air conditioning. Mechanisms to aid heat loss include tepid sponging to aid evaporation, fans to enhance convection loss, and the ingestion of cool drinks. In severe hyperpyrexia, immersion in a cold bath may be needed.

\section{Hyperhidrosis}

Management depends upon the underlying cause, the sites involved, and the functional and emotional disability. In localised hyperhidrosis over the palms and soles, astringents containing glutaraldehyde and antiperspirants containing aluminium salts may reduce sweating. Iontophoresis has been used in palmar and plantar hyperhidrosis. Low dose pharmacotherapy includes anticholinergics and centrally acting sympatholytics. The former include probantheline bromide in a dose of $15 \mathrm{mg}$ three times daily. Side effects include a dry mouth. Glaucoma should be excluded before use. Low dose clonidine (25-50 $\mu \mathrm{g}$ three times daily) may benefit those with a central or emotional component, and also may reduce facial flushing. Topical anticholinergic cream (hyoscine hydrobromide or glycopyrrolate) may be helpful in localised hyperhidrosis. Botulinum toxin is successful in hyperhidrosis affecting the axillae, palms, and face; injections may need to be repeated.

When these measures fail, surgical intervention using percutaneous endoscopic transthoracic sympathectomy, with ablation of prevertebral sympathetic ganglia from T2 to T4, should be considered. Ablation of $\mathrm{Tl} / \mathrm{T} 2$ also is used in facial flushing. In some, compensatory hyperhidrosis below the anhidrotic region can be extremely troublesome.

\section{ALIMENTARY SYSTEM}

Xerostomia is helped by artificial saliva. Excessive salivation responds to botulinum injection. Achalasia of the oesophagus may require dilatation, botulinum injection or surgery. In MSA with oropharyngeal dysphagia, advice should be provided on the type and consistency of food; severe dysfunction increases the risk of tracheal aspiration and a feeding percutaneous enterogastrostomy tube may be needed. The dopamine antagonists, metoclopramide and domperidone, increase gastric emptying in gastroparesis, as does the macrolide erythromycin that stimulates motilin receptors. Peptic ulceration occurs in the early stages after high spinal cord injury and prophylaxis includes $\mathrm{H}_{2}$ antagonists (cimetidine and ranitidine) and proton pump inhibitors (omeprazole). In diarrhoea caused by bacterial overgrowth, as in the blind loop syndrome, broad spectrum antibiotics (neomycin or tetracycline) may be the initial step before using codeine phosphate or other opiate based antidiarrhoeal agents. The somatostatin analogue, octreotide, may reduce diarrhoea in amyloidosis and diabetic autonomic neuropathy. Aperients and laxatives, together with a high fibre diet, are needed in constipation.

\section{URINARY TRACT}

In outflow tract obstruction, procedures that include prostatectomy, transurethral resection, or sphincterotomy may be needed. Surgical procedures often induce or worsen incontinence in MSA. Bladder dysfunction may be helped by drugs that influence detrusor muscle activity (anticholinergics) or 
Table 4 Management strategies in autonomic diseases that affect multiple systems

\begin{tabular}{|c|c|}
\hline Specific & $\begin{array}{l}\text { For orthostatic hypotension, and bladder, bowel and sexual } \\
\text { dysfunction } \\
\text {-non-pharmacological and pharmacological therapy } \\
\text { For respiratory abnormalities: consider tracheotomy } \\
\text { For oropharyngeal dysphagia: consider PEG }\end{array}$ \\
\hline - General & For depression \\
\hline Education & $\begin{array}{l}\text { Of patients and partners, relatives, carers, medical practitioners, } \\
\text { supportive therapists, to include physiotherapists, occupational } \\
\text { therapists, speech therapists and dietitians }\end{array}$ \\
\hline $\begin{array}{l}\text { Autonomic nurse specialists and } \\
\text { autonomic liaison nurses }\end{array}$ & To coordinate and streamline care between hospital and home \\
\hline D Patient support groups & $\begin{array}{l}\text { To disseminate information and increase awareness } \\
\text {-Autonomic Disorders Association, Sarah Matheson Trust in UK } \\
\text {-National Dysautonomia Research Foundation, USA } \\
\text {-Shy-Drager Association, USA } \\
\text {-Syncope and Reflex Anoxic Seizures (STARS) Trust, UK }\end{array}$ \\
\hline
\end{tabular}

sphincter malfunction ( $\alpha$ blockers). Intermittent or indwelling catheterisation may be necessary. Nocturia in primary autonomic failure may be helped by intranasal or oral desmopressin given in the evening.

\section{SEXUAL FUNCTION AND THE REPRODUCTIVE SYSTEM}

Erectile failure in men can be treated by suction devices, an implanted prosthesis, or drugs. The latter can be given locally (intracavernosal or urethral) or orally (sildenafil). Sildenafil and allied drugs have the potential through vasodilatation to lower blood pressure substantially, especially in patients with orthostatic hypotension. In DBH deficiency, difficulty in ejaculation is improved by treatment with L-DOPS (L-theodihydroxphenylserine). Pregnant women with high spinal injuries may develop severe hypertension with cardiac dysrhythmias and eclampsia during uterine contractions and delivery. Spinal anaesthesia, which reduces spinal sympathetic discharge, often permits a normal delivery without the cardiovascular features of autonomic dysreflexia.

\section{RESPIRATORY SYSTEM}

A tracheostomy may be necessary in severe inspiratory stridor caused by laryngeal abductor paresis, especially when oxygen desaturation occurs at night. With periodic apnoea, timed or triggered bilevel positive airway pressure ventilation may be useful. In high spinal cord lesions on artificial ventilation, particular care should be taken during tracheal suction and toilet, to avoid bradycardia and even cardiac arrest. In ventilated tetanus patients the reverse, tachycardia and hypertension, may occur.

\section{EYE AND LACRIMAL GLANDS}

In alacrima, tear substitutes such as hypromellose eye drops are needed. Cycloplegia can be reduced by local cholinomimetics. Patients should be made aware of night blindness in sympathetic denervation and about a low threshold to sunlight in parasympathetic denervation of the pupils.

\section{ADDITIONAL NEUROLOGICAL DEFICITS}

In the parkinsonian forms of MSA, L-dopa is often of benefit in the early stages. It may, however, cause or enhance orthostatic hypotension and ideally should be used with higher doses of decarboxylase inhibitors. The monoamine oxidase B inhibitor, selegiline, has been used in combination with L-dopa and also may worsen orthostatic hypotension. It also may cause hypertension in Parkinson's disease by mechanisms that include the central effects of its metabolite, methyl-amphetamine. Amantidine may provide motor benefit without lowering blood pressure. Dopaminergic agonists may be effective but it is unclear if they worsen orthostatic hypotension. With time there often is refractoriness to anti-parkinsonian drugs in MSA. There is no effective pharmacotherapy for cerebellar deficits in MSA. Supportive therapy using disability aids should be provided.

There is limited evidence that transplantation of the pancreas in diabetes mellitus, and of the liver in familial amyloid neuropathy, may halt the neuropathy in these otherwise relentlessly progressive disorders.

\section{CONCLUSION}

The management of autonomic diseases needs to consider local organ dysfunction, the underlying or associated disease, and integrative components often needing specialist care involving different specialities (table 4). Of particular importance, especially in the generalised disorders, is the need for a holistic approach. Management should involve not only the patient, but the family, carers, and the community.

\section{REFERENCES AND FURTHER READING}

1 Adar R. Compensatory hyperhidrosis after thoracic sympathectomy. Lancet 1997;351:231-2.

2 Alam M, Smith GDP, Bleasdale-Barr K, et al. Effects of the peptide release inhibitor, octreotide, on daytime hypotension and on nocturnal

hypertension in primary autonomic failure. J Hypertens 1995;13:1664-9.

3 *Appenzeller O, Oribe E, eds. The autonomic nervous system. An introduction to basic clinical concepts, 5th ed. Amsterdam: Elsevier Medical Press 1997.

4 Churchyard A, Mathias CJ, Boonkongchuen P, et al. Autonomic effects of selegiline: possible cardiovascular toxicity in Parkinson's disease. J Neurol Neurosurg Psychiatry 1997;63:228-34

5 Colosimo C, Pezzella FR. The symptomatic treatment of multiple system atrophy [review]. Eur J Neurol 2002;9:195-9.

6 Cooper VL, Hainsworth R. Effects of dietary salt on orthostatic tolerance, blood pressure and baroreceptor sensitivity in patients with syncope. Clin Aut Res 2002;12:234-41.

7 Benditt DG. Cardiac pacing for prevention of vasovagal syncope. J Am Coll Cardiol 1999; 33:21-3.

8 Harcourt J, Spraggs P, Mathias CJ, et al. Sleep-related breathing disorders in the Shy-Drager syndrome. Observations on investigation and management. Eur J Neurol 1996;3:186-90. 
9 *Low PA, ed. Clinical autonomic disorders, 2nd ed. Philadelphia: Lippincott, Raven, 1997.

10 Low PA, Gilden JL, Freeman R, et al. Efficacy of midodrine vs. placebo in neurogenic orthostatic hypotension. A randomized, double-blind multicenter study. JAMA 1997;277:1046-51.

11 Mathias CJ. A 21 st century water cure. Lancet 2003;356:1046-8.

12 *Mathias CJ, Bannister R, eds. Autonomic failure: a textbook of clinical disorders of the autonomic nervous system, 4th ed. Oxford: Oxford University Press, 2002

13 *Mathias CJ, Kimber JR. Treatment of postural hypotension. J Neurol Neurosurg Psychiatry 1998;65:285-9.

14 Mathias CJ, Senard J, Braune S, et al. L-theo-dihydroxphenylserine (L-threo-DOPS; droxidopa) in the management of neurogenic orthostatic hypotension: a multi-national, multi-centre, dose-ranging study in multiple system atrophy and pure autonomic failure. Clinical Autonom Research $2001 ; 11: 235-42$.

15 Mathias CJ, Young TM. Plugging the leak - benefits of the vasopressin -2 agonist, desmopressin in autonomic failure. Clin Aut Res 2003;13:85-7.
16 Oldenburg O, Mitchell AN, Nurnberger J, et al. Ambulatory norepinephrine treatment of severe autonomic orthostatic hypotension. J Am Coll Cardiol 2001;37:219-23.

17 Perhonen MA, Zuckerman JH, Levine BD. Deterioration of left ventricular chamber performance after bed rest: 'cardiovascular deconditioning' or hypovolemia? Circulation 2001;103:1851-7.

18 Shannon JR, Diedrich A, Biaggioni I, et al. Water drinking as a treatment for orthostatic syndromes. Am J Med 2002;1 12:355-60.

19 Tugnoli V, Marchese Ragona R, et al. The role of gustatory flushing in Frey's syndrome and its treatment with botulinum toxin type A. Clin Aut Res 2002;1 2:174-8.

20 van Dijk N, Harms MP, Linzer M, et al. Treatment of vasovagal syncope: pacemaker or crossing legs? Clin Aut Res 2000;10:347-9.

21 Wieling W, van Lieshout JJ, Hainsworth R. Extracellular fluid volume expansion in patients with posturally related syncope. Clin Aut Res 2002; 12:242-9.

${ }^{*}$ Recommended

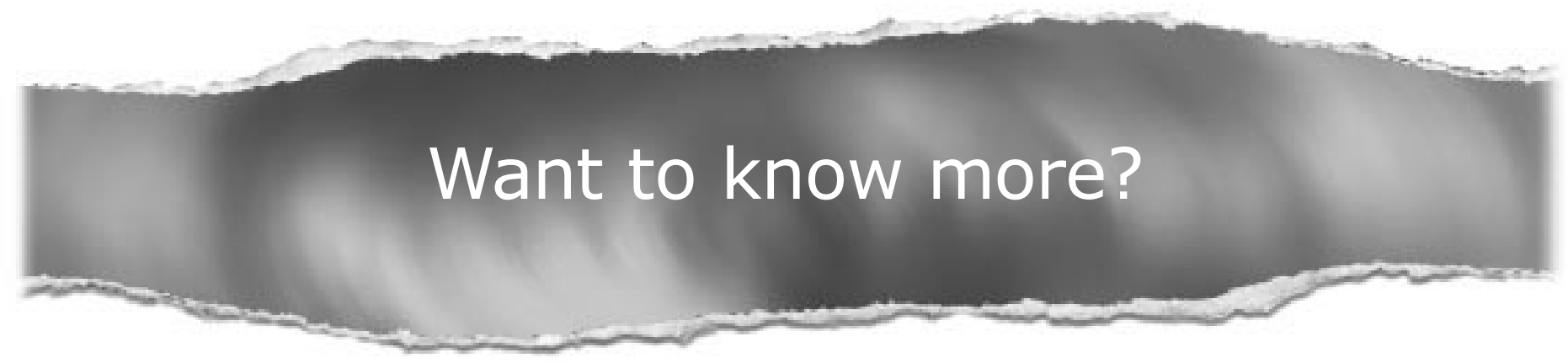

Data supplements

Limited space in printed journals means that interesting data and other material are often edited out of articles; however, limitless cyberspace means that we can include this information online. Look out for additional tables, references, illustrations.

\section{www.jnnp.com}

